Rhode Island College

Digital Commons @ RIC

Master's Theses, Dissertations, Graduate

Master's Theses, Dissertations, Graduate Research and Major Papers Overview

Research and Major Papers

$1-1-2011$

\title{
The Perceived Impact of Diabetes Support Groups
}

Rebecca Garofalo

Rhode Island College

Follow this and additional works at: https://digitalcommons.ric.edu/etd

Part of the Public Health and Community Nursing Commons

\section{Recommended Citation}

Garofalo, Rebecca, "The Perceived Impact of Diabetes Support Groups" (2011). Master's Theses, Dissertations, Graduate Research and Major Papers Overview. 206.

https://digitalcommons.ric.edu/etd/206

This Major Paper is brought to you for free and open access by the Master's Theses, Dissertations, Graduate Research and Major Papers at Digital Commons @ RIC. It has been accepted for inclusion in Master's Theses, Dissertations, Graduate Research and Major Papers Overview by an authorized administrator of Digital Commons @ RIC. For more information, please contact digitalcommons@ric.edu. 
THE PERCEIVED IMPACT OF DIABETES SUPPORT GROUPS

A Major Paper Presented

By

Rebecca Garofalo

Approved:

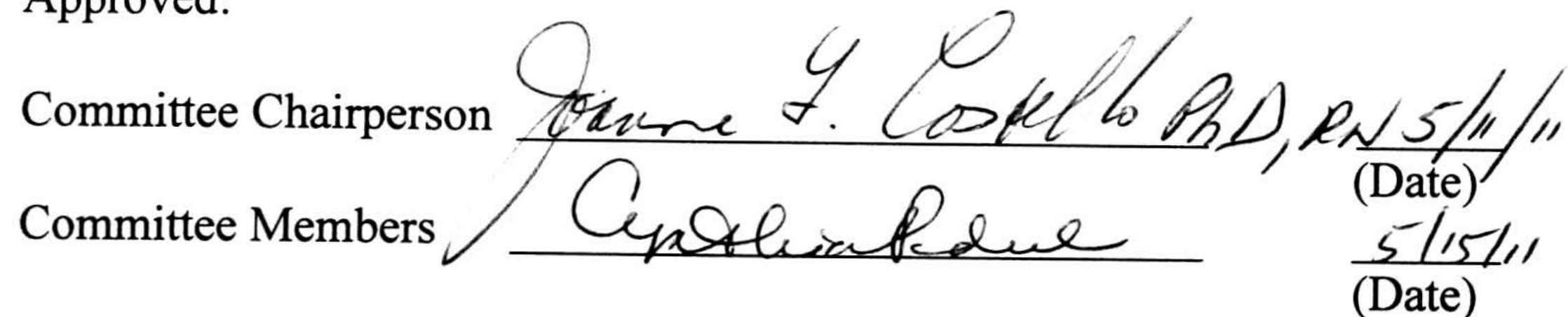

Mavew Bowia M. Ed RNCDE $\frac{5-11-11}{\text { (Date) }}$

Director of Master's Program Cepaluabdeee $\frac{5 / 15 / \text { "1 }}{\text { (Date) }}$

Dean, School of Nursing the Whim $\frac{7 / 28 / 11}{(\text { Date) }}$ 
THE PERCEIVED IMPACT OF

DIABETES SUPPORT

GROUPS

By

Rebecca Garofalo RN, BSN

A Major Paper Submitted in Partial Fulfillment

of the Requirements for the Degree of

Master of Science in Nursing

in

The School of Nursing

Rhode Island College 


\section{Abstract}

A dearth of research exists describing the perceived impact of diabetes support groups from the perspective of support group participants. This study examined the subjective experience of being a participant in a diabetes support group upon a person's physical and emotional well being. Participants were recruited from a diabetes support group and interviewed individually through a series of open ended interview questions. The participants reported various physical and emotional challenges related to their diabetes. The support group was a source of information, hope, shared experience and group problem solving as individuals strived to maintain lifestyle behaviors required to manage their diabetes. This support group was a positive source of support for these participants. More studies, with larger sample sizes, examining support group interventions or strategies would be beneficial in order to gain an understanding of which aspects of a support group promote positive client outcomes. Advanced practice nurses play a pivotal role in designing further studies that examine the impact of support groups. This will enhance our understanding of a support group's role in sustaining and promoting positive health behaviors and well being. In order to continue this form of support in the community, health policy needs to address the funding of this resource to sustain it as a tertiary intervention in the future. 


\section{Acknowledgements}

First and foremost, I am thankful to Dr. Joanne Costello, my major advisor, for her guidance and expertise on this project. Her knowledge of a subject most near and dear to her has enlightened my awareness and understanding of this very important and significant public health issue. Her expertise in qualitative research methods has been instrumental in this process and has provided a means in which I was able to conceptualize the lived experience of a person afflicted with diabetes. Secondly, I wish to thank Dr. Patricia Thomas, my second reader for her suggestions and insight. Her knowledge and general enthusiasm is very much appreciated. Lastly, I would like to thank Maureen Boris RN MS, Certified Diabetes Outpatient Educator, not only for her guidance and expertise, but her willingness to welcome me into her beloved diabetes support group.

Many others have inspired and assisted me in pursuit of a graduate degree for which I am grateful. This experience at Rhode Island College has enriched my depth of knowledge and has fostered my appreciation of the art and science of nursing. 
Table of Contents

Background and Problem

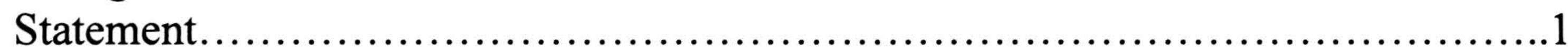

Literature Review................................................................

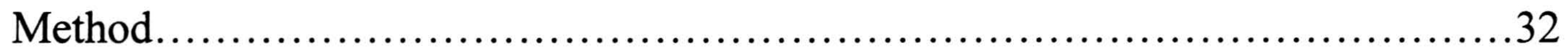

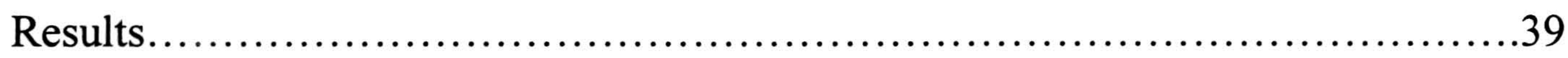

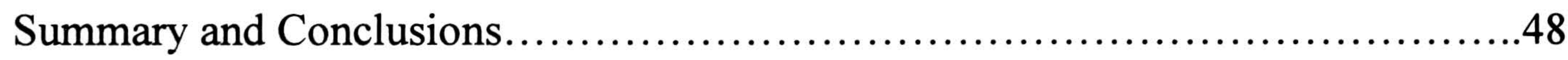

Recommendations for Advanced Practice Nursing ............................53

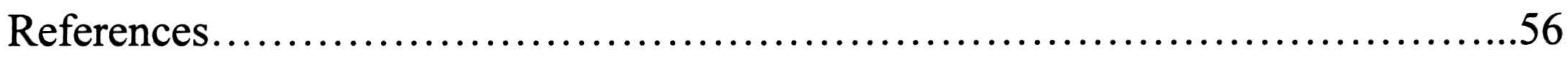

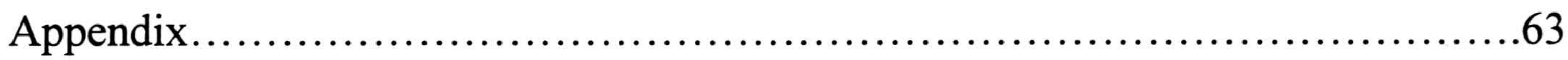


The Perceived Impact of Diabetes Support Groups

\section{Background/Statement of the Problem}

Diabetes is a chronic disease that affects millions of Americans. It is not one disease, but is actually a group of metabolic diseases in which hyperglycemia or elevated blood sugar outside of the range of normal results from defects in the body's production of insulin, insulin action or a combination of both (American Diabetes Association [ADA], 2010). Both physical and mental well-being are affected. Depression is a common element when coping with a chronic illness such as diabetes and must be controlled in order for a person to effectively manage the disease.

The intricacies of diabetes will differ from individual to individual; however lasting lifestyle change is a common element necessary for all people living with diabetes (American Association of Diabetes Educators [AADE], 2010). In fact, the National Standards for Diabetes Self-Management Education recommend ongoing support for persons living with diabetes (Funnel et al., 2010). Coping with diabetes may require a particular skill set that can be achieved through meeting others with the same condition through participation in activities such as support groups. Support groups may represent a source of psychological and social support for persons living with diabetes. Costello (2007) stated that although support groups have educational components, their main focus is psychological support. Clients attend for varying lengths of time and a professional facilitator leads the group process (Costello, 2007). 
A substantial amount of evidence has shown the positive benefit diabetes selfmanagement educational groups have had on clinical diabetes outcomes and perceived quality of life, but there is a dearth of literature that describes the impact diabetes psychological support groups have had upon those same outcomes. How does being in a support group help persons living with diabetes to cope with the emotional and physical sequelae that often come with chronic illness and how do persons living with diabetes feel about attending these support groups? The purpose of this study was to explore the perceived impact of diabetes support groups among participants. 


\section{Review of the Literature}

\section{Databases}

A literature search of the following databases was conducted: CINAHL; Medline; Academic Search Complete; Academic Search Premier; from 2000-2011 using key words diabetes self management, education, coping, and support group.

\section{Epidemiology}

Diabetes is a significant public health problem. In $2010,8.3 \%$ of the population were affected with diabetes (Centers for Disease Control and Prevention [CDC], 2011). This total consisted of 18.8 million people who had diabetes and 7.0 million of whom were undiagnosed (CDC). Diabetes was the seventh leading cause of death among all Americans when adjusted for age (CDC, 2007a), and 71,382 Americans died as a result of diabetes related complications in 2007. The magnitude of diabetes and how it affects the mortality of Americans is underestimated. Diabetes is underreported, with only 35$40 \%$ of decedents' death certificates reflecting diabetes as a cause of death have it listed (CDC, 2007). Co-morbid conditions frequently occur with the disease which is the number one cause of new cases of blindness, the leading cause of kidney failure and nontraumatic lower limb amputations, as well as a major contributing factor for heart disease and stroke (CDC, 2011).

In addition to health related burdens, diabetes has significant economic implications. A total of $\$ 174$ billion was spent in direct and indirect medical costs, $\$ 116$ billion of which was spent on costs related to direct medical care in 2007 . Indirect costs 
include time lost from work, early disability, and premature death, which totaled costs of $\$ 58$ billion in 2007 (CDC, 2007a). Medical expenditures are more than two times higher for people who have diabetes than for people without diabetes (CDC, 2011). Prediabetes is another major health concern. Pre-diabetes, often a precursor to diabetes mellitus, is a condition in which a person's blood glucose is higher than normal, but not elevated enough to qualify for a diagnosis of diabetes (CDC). This condition is concerning because people with elevated blood glucose have a higher risk of cardiovascular disease (ADA, 2010). In the US, there were 79 million people with prediabetes in 2010 (CDC, 2011).

\section{Diabetes Self Management}

Lasting lifestyle change is required to manage diabetes. People with diabetes must cope with a range of challenges that are affected by many variables including social, behavioral, economic, and familial among others (Fisher, Thorpe, Devellis, \& Devellis, 2007). Fisher et al. (2007) stated that these challenges could influence diabetes management and metabolic control. The AADE (2010) recognizes seven behaviors that are required for diabetes management. These include healthy eating, physical activity, monitoring, taking medication, problem solving, healthy coping, and reducing risks (AADE). Successful management is essential to minimize long-term complications from diabetes. In order to successfully manage diabetes, these seven behaviors must be incorporated into the lifestyle of a person living with the disease (AADE). 
Various definitions of diabetes self-management exist in the literature. Harris et al. (2000) noted that diabetes self-management encompasses the behaviors displayed by a patient or family members that are directed at the establishment and maintenance of glucose control and disease monitoring in order to prevent or correct deviations from target blood sugar levels. This involves making daily decisions regarding care in a person's usual living environment. In recognition of the serious nature of this public health problem, in 2002 the CDC launched a national campaign to educate the public about the seriousness of diabetes. Entitled "Take Charge of Your Diabetes," it is targeted to educate patients who have diabetes and urges people with diabetes to become selfmanagers of their condition (CDC, 2007b). Healthy People 2020, a set of health priorities for the nation to achieve between 2010-2020, cited the continued need to improve the overall care of people with diabetes in order to reduce the complications of diabetes (USDHHS, 2009). Additional objectives not present on the Healthy People 2010 agenda are lipid and blood pressure considerations as well as looking at individual risk behaviors in those who are pre-diabetic or who have multiple risk factors (USDHHS).

Evidence regarding the impact of glycemic control on long-term complications from diabetes has been extremely positive. The Diabetes Control and Complications Trial (DCCT) was a ten-year landmark study that involved 1,441 volunteers with type 1 diabetes ages 13-39 with no or minimal sign of diabetes related eye disease. Comparisons were made between those who underwent traditional glycemic control (insulin injections 
up to twice daily) with those who were maintained by tight glycemic control (continuous insulin infusions or multiple injections daily) over 10years (National Institute of Diabetes and Digestive and Kidney Diseases [NIDDKD], 2008). The study concluded that marked reductions in complications from diabetes could be obtained with tight glycemic control. The risk of retinopathy was decreased by $70 \%$ in the group that underwent tight glycemic control. There was a $42 \%$ risk reduction for macrovascular events combined and $78 \%$ risk reduction for cardiac events in this group as well. This study was a landmark success, as it became the driving force for practitioners to understand that complications of diabetes can be avoided through directed interventions aimed at lowering blood sugars. It also provided evidence that lifestyle changes are worth the effort and reinforced the idea that individual self-management behaviors and lifestyle changes are essential components of glycemic control.

The UK Prospective Diabetes Study (UKPDS), initiated in 1997, attempted to confirm that the same positive outcomes of tight glycemic control seen in those with type 1 diabetes were also true for individuals living with type 2 diabetes. The study was a randomized trial of 5,102 persons with newly diagnosed diabetes (UKPDS, n.d.). Subjects were randomized to receive intensive pharmacological treatment to reduce glucose or conventional diet with the addition of pharmacotherapy only if a fasting glucose exceeded $270 \mathrm{mg} / \mathrm{dl}$. This study extended over a ten year period. Participants treated with Metformin had a 39\% risk reduction for myocardial infarction and a $42 \%$ risk reduction for diabetes-related deaths. 
The Diabetes Prevention Program (DPP) was a monumental study which showed the positive effects of lifestyle change among those who have impaired glucose tolerance (Knowler et al., 2002). This experiment involved studying the effects of lifestyle change compared with medication management with Metformin among subjects with prediabetes. Over 3,000 participants from 27 clinical sites across the US who had impaired glucose tolerance were randomly assigned to one of three conditions: lifestyle change with the aim of diet and exercise for 150 minutes per week; treatment with Metformin, a drug used to lower blood sugar; or placebo. The two latter groups received information diet and exercise. Astoundingly, the study confirmed that millions of high risk people can delay or avoid type 2 diabetes by regular physical activity and a diet low in fat and calories. Losing just $5 \%-7 \%$ of body weight through lifestyle modification resulted in a $58 \%$ reduction in diabetes incidence among this population. The use of Metformin was also effective in reducing the incidence of type 2 diabetes among this population by $31 \%$. The findings were true across ethnic groups. Only $5 \%$ of the intervention group developed diabetes each year compared to $11 \%$ of the placebo group. An important concept learned from this study was that lifestyle change resulting in significant weight reduction could stop or delay the onset of diabetes and signifies the need to stress lifestyle change as being an essential component of diabetes management.

\section{Diabetes Self Management Education}

Diabetes self-management education is a standard of care that is recommended by the ADA for all individuals living with diabetes. It incorporates guiding principles 
such as making decisions, behaviors promoting self-care, problem-solving, and active collaboration (Funnel et al., 2010). Diabetes self-management is an ongoing process (Funnell et al., 2010). It involves providing knowledge and skills that a client can use so that they learn how to manage their needs (Ellis et al., 2003). A task force jointly convened in 2006 with the ADA and the AADE to review and further develop The National Standards of Diabetes Self-Management Education on an ongoing basis. These guidelines are reviewed and revised approximately every five years according to the evidence and offer guiding principles to diabetes self management education (Funnel et al., 2010). Due to the complexity of the disease, an integrated approach is required for proper management. The National Standards for Diabetes Self-Management Education recommends both diabetes self-management education and the use of ongoing support. Both are crucial to someone living with diabetes (Funnel et al.).

Historically in the 1970's, diabetes education consisted of an inpatient course which was viewed as an acceptable means in which to educate individuals with diabetes. Often a nurse and nutritionist performed this training with the hope that a person with diabetes could function at home (Mensing \& Norris, 2003). Traditional education used was didactic or a lecture style approach. According to Calabretta (2002), there has been a substantial shift in diabetes education to outpatient settings. It is conducted by a variety of trained individuals including lay people and medical professional who facilitate the learning process. Diabetes self-management education has evolved to incorporate strategies to promote behavior change as it has been found that imparting information 
alone is not enough to promote self- management (Calabretta). Educational interventions that have traditionally followed a lecture type format have now moved to a collaborative format where patients are actively engaged in the learning process through interactive role playing and group discussions (Garrett et al., 2005). The National Standards for Diabetes Self-Management Education (Funnel et al., 2010) claim that currently there is no best known approach to education. However, they advocate for programs that are based on behavioral and psychosocial strategies.

Diabetes self-management education is a concept that has received great attention over the past decade. The Balanced Budget Act of 1997 was a piece of legislation that provided reimbursement for diabetes education under the Medicare Program and was the impetus for other insurer-driven reimbursement of diabetes education in the United States (Leichter, 1999). This legislation served as an initial point of entry for many living with diabetes to receive education on an outpatient basis.

\section{Health Effects of Individual and Group Diabetes Self-Management Education}

In a systematic review, Deakin, McShane, Cade, and Williams (2005) studied the effects of self-management training on self-management strategies in a group setting. Eleven studies met the inclusion criteria, and the authors evaluated clinical, lifestyle, and psychosocial outcomes. Studies that included education in groups of six or more were included. Educational approaches differed in intensity and location as well as whether family members were included. The study demonstrated short-term (at 4-6 months) and long-term (greater than 12 months) impacts after group interventions. The authors 
reported that group training significantly impacted short term lowering of blood pressure. A reduced need for diabetes medication, improved fasting blood sugars, improved glycemic control, and diabetes knowledge at short and long term follow up were also reported. At longer follow up, there were improvements in self-efficacy, treatment satisfaction, and quality of life. Differences in results were not detected according to who taught the courses or the size of the group (Deakin et al.).

Clark (2008) performed a systematic meta-analysis of individual and group diabetes self-management education upon knowledge, emotional state, and metabolic control. The review included three meta-analyses, seven primary studies, and seven systematic reviews of different educational interventions in either individual or group format. The participants had either type 1 or type 2 diabetes. Knowledge and skill effects lasted for up to at least one year, while weight improvements decreased after six months. Peak metabolic control occurred between one and six months and then declined. Psychological outcomes such as decreased depression and quality of life were improved over time. Younger patients had evidence of more knowledge with older patients. Knowledge and skill were not found to be predictors of diabetic control in the long term. There was no consistency or pattern based on the type of intervention or duration, setting or other characteristics; thus, it was not possible to identify what strategy was most effective for improving diabetes control.

Clark (2008) suggested that it is difficult to evaluate the results of diabetes selfmanagement education as most studies involved heterogeneous populations and mixed 
educational strategies upon a variety of outcomes in both individual and group settings. However, in general, this meta-analysis suggested that both group and individual diabetes self- management education are effective and produce similar effects. The authors suggested that education needs to be geared according to the needs of the client and that education should be an ongoing process.

Norris, Lau, Smith, Schmid, and Engelgau (2002) performed a meta-analysis of randomized controlled trials to examine the effects of various individual and group diabetes self-management educational strategies on diabetic control in adults with type 2 diabetes. Thirty-one studies met selection criteria. The study provided evidence that diabetes self-management education among persons with type 2 diabetes was effective upon glycemic control. Results indicated that diabetes self-management education improved the $\mathrm{HbAlc}$, with an average change of $-0.76 \%$ when measured immediately post intervention. The only significant variable contributing to this was contact time with educator. On average, 23.6 hours of contact time was required between the educator and the participant to reduce the absolute $\mathrm{HbAlc}$ by $1 \%$ (Norris et al.). Other variables, such as length of time the classes were delivered over, who delivered the education, educational focus, or setting were not significant. The effects of diabetes selfmanagement education diminished over time. This study provided evidence that educational strategies need to allow adequate contact time between diabetes educators and their patients. 


\section{Coping and Diabetes}

An abundance of literature exists describing the emotional response and coping skills among individuals with diabetes. Dealing with diabetes and other chronic illness requires ongoing coping to respond to the inherent challenges of the disease. Coping according to Lazarus and Folkman (1984) is defined as the "constantly changing cognitive and behavioral efforts to manage specific external and /or internal demands that are appraised as taxing or exceeding the resources of the person" (p. 141). It is the how the stressor or event is appraised that attaches meaning and this differs among individuals (Lazarus \& Folkman, 1984).

Studies have shown mixed results regarding coping and its effect upon diabetic control. Sanden- Erikkson (2000) examined the relationship between emotional state and control over diabetes among a group of 83 individuals with type 2 diabetes. The authors analyzed sense of coherence or "health perspective" and metabolic control of the disease. Antonovsky (1979) described origins or views of health as either having a salugenic approach, where health is looked at on a continuum and a person strives to maintain health through dealing with stressors, or a pathogenic approach, which focuses on what causes a person to become ill (Antonovsky). He postulated that a person's sense of coherence (SOC) is also a relevant factor and can affect whether a person has a salugenic or pathogenic focus to health. According to Antonovsky, SOC is as a way to look at life and one's position in the world and it is affected by the personality. The personality is a 
relatively stable trait with temporary situations that could affect an individual and cause a temporary shift in SOC.

Antonovsky (1979) believed that a strong SOC predicted how a person would handle stress and where a person would lie on the health-disease continuum. SandenEricksson (2000) found a correlation between SOC, self assessed health, and HbAlc $(\mathrm{p}<.02)$. Self-assessed health was a direct indicator of higher SOC scores and lower $\mathrm{HbAlc}$. Additionally, there was a positive correlation between lower $\mathrm{HbAlc}$ and higher levels of active disease management and emotional acceptance of the disease $(\mathrm{p}<0.01)$.

Macrodimitris and Endler (2001) explored the relationships among coping, illness control (perceived or actual) and psychological adjustments in a sample of 115 clients with type 2 diabetes. $\mathrm{HbA} 1 \mathrm{c}$ tests results were reported by participants. Results indicated that problem-focused (instrumental) coping strategies were related to better psychosocial outcomes such as decreased depression and anxiety. Instrumental coping was negatively associated with depression $(r=-.21, p<.05)$. Conversely, palliative coping $(p<.01)$ and emotional preoccupation coping $(p<.001)$ were positively related to anxiety and depression. High perceived control was the only negative predictor of $\mathrm{HbAlc}$ $(-2.28, \mathrm{p}<.05)$. Participants who had higher perceived control and low emotional preoccupation coping styles had lower $\mathrm{HbAlc}$.

Macrodimitris and Endler (2001) made a connection between the results of this study and the "goodness of fit hypothesis" (Conway \& Terry, 1992) showing that there are correlations among perception of control, coping strategies, and outcome variables, 
and that problem and emotion focused coping strategies are not the only predictors of control among persons living with diabetes. Interestingly, they reported stressors perceived as controllable were best dealt with through problem focused coping strategies, whereas avoidance or emotion focused coping strategies were more effective for stressors perceived as uncontrollable.

In a systematic review, Duangdao and Roesch (2008) examined the relationship between coping types and evidence of psychological and glycemic control. Twenty- one studies that involved a total of 3,381 persons living with diabetes were included. Problem focused approaches to coping were associated with better overall psychological adjustment to the disease with a mean effect size of 0.13 . The use of approach coping was associated with better diabetic control with a mean effect size of 0.17 (Duangdao \& Roesch). The authors concluded that better psychological and physical outcomes among persons with diabetes are fostered when individuals use a directive approach to manage their disease.

\section{Diabetes Support Groups}

Diabetes support groups have been in existence since the 1970's and can be structured in different ways: formal with some educational component or informal, primarily focusing on psychosocial issues, with group support and trained health personnel acting as facilitators (Costello, 2007). Diabetes Standards of Care guidelines recommend groups as one method of continuing the effects of diabetes education and self-management training (Funnel et al., 2010). While the primary educational tool for 
individuals with diabetes is the participation in diabetes education and self-management training, support groups have been found to be an additional source of support for those living with diabetes and offer an environment for people with diabetes to learn together (Mensing \& Norris, 2003).

Evaluation of diabetes support groups remains a gray area. As in the difficulties that exist with evaluating diabetes self-management education programs, the varied nature of the structure and content of diabetes support groups allows for mixed interpretation of results (Alley \& Brown, 2002). Alley and Brown recognized that diabetes support groups leave some questions as to their effectiveness due to "methodological issues." This creates an uncertainty regarding precisely how support groups function, and it is not known exactly how support groups affect clients and to what extent, if any, they help to decrease psychosocial challenges. An additional concern (Alley \& Brown) was that most studies of support groups were evaluations of how the glucose levels changed as opposed to assessing the psychosocial changes which may have occurred.

Gamsu, Sutton, and Ward (2002) performed a study that looked at the effects of a psycho-educational group intervention for women with type 2 diabetes who had a BMI between 30-40, a history of unsuccessful dieting, and a personal dissatisfaction with weight and self-image. Twenty women were divided among two groups for the purpose of keeping the groups small and not for the purpose of comparing differences. Both groups underwent the same sessions of weekly education lasting two hours for a period of 
three months. Content was focused on improving self-esteem, decreasing body dissatisfaction, psychosocial influences of diabetes, healthy eating, healthy weight, and activity. Psychological outcomes were significantly improved from pre-study measures. The participants experienced decreased difficulty with socializing, decreased dependency, and increased self esteem as a result the sessions. Upon completion of the group sessions, the participants reported that the group process helped to decrease feelings of isolation and fostered an arena for sharing of experiences. There were no significant differences in $\mathrm{HbA1C}$, LDL or weights after the three month intervention (Gamsu,Sutton, \& Ward).

Trozzolino, Thompson, Tansman, and Azen (2003) performed a randomized controlled study of 48 participants with low visual acuity to see what effects a 12 week psycho-educational program would have on improving mood and glycemic control. Using a two-group design, the experimental or "vision maximizer" group and the control group received eye exams, visual aids, rehabilitation strategies, and devices to manage diabetes at home. The "vision maximizer group" also received 10 sessions of cognitive behavioral therapy in a group setting, one session of basic diabetes care, and one session of diabetes information.

Psychological sessions focused on factors that influence care of diabetes such as attitude, relationships with healthcare professionals, and social support. Participants in both groups were assessed baseline and 12 weeks post intervention for depression and diabetes knowledge using validated instruments. Results indicated that participants in 
the vision maximizer group had statistically significant decreases in problem areas in diabetes (PAID) scores $(\mathrm{p}<.01)$ and HbAlc $(\mathrm{p}<.001)$. There was also a correlation between a decrease in depression and a decrease in $\mathrm{HbAlc}(\mathrm{p}<.04)$. There were no statistically significant changes observed in the control group. Increased knowledge did not correspond with improved glycemic control, confirming other studies and suggesting that imparting information alone is not enough.

Sarkadi and Rosenqvist (2004) performed a year-long randomized control study with 77 participants who had type 2 diabetes. The experimental group received monthly support which focused on sharing glucose reports and group problem solving as well as instruction in diabetes management and dealing with emotional aspects of diabetes. The impact of these interventions on long term (greater then 3-6 months) metabolic outcomes was examined. The experimental group had a year-long pharmacist-led intervention that was based on participants' experiences of glucose regulation during monthly group session. $\mathrm{HbAlc}$ was measured via questionnaire at $0,6,12$, and 24 months as well as at baseline and final follow up. The control group received no intervention. The authors found that experience based group education and monthly support was instrumental in decreasing the $\mathrm{HbA} 1 \mathrm{C}$ at six months and also at one year following group intervention. These changes were more pronounced for those in the intervention group then those in the control group. At 24 months after baseline measurements, there was a $0.8 \%$ decrease in $\mathrm{HbA} 1 \mathrm{C}$ in the intervention group versus a $0.1 \%$. decrease among those in the control group. 
THE PERCEIVED IMPACT OF DIABETES

Kotani and Sakane (2004) examined the effects of a mixed support group that consisted of group motivation along with monthly education on a range of topics including exercise, nutrition, stress management, and other related topics. Nine subjects who chose to participate were compared to six subjects who choose not to participate. The authors reported a $0.4 \%$ decrease in $\mathrm{HbAlC}$ at 24 months after the intervention as compared to baseline among subjects who attended the educational self-help group compared to those who did not attend.

Garrett et al. (2005) evaluated the effectiveness of an interactive group intervention on participants' knowledge, feeling of control, and behavior versus the effectiveness of reading self-care book upon the same outcomes. The authors utilized a randomized design with pre and post test. Three hundred and fifty-eight patients were assigned to the intervention group and 382 to the control group. The intervention group participated in a three hour learning map process, which is a participatory process of discussion, dialogue, and shared experiences. Overviews of diabetes as well as potential complications were discussed as well as pathophysiology of the disease. The control group received a diabetes self care book. Pre- intervention, both groups had similar knowledge of diabetes care and had similar diabetes care practices. The intervention group demonstrated greater improvement in knowledge following the intervention versus the control group with mean increases of 1.4 vs 0.7 respectively (Garrett). Other areas of improvement included knowledge of diabetes care, feelings of control over diabetes and diabetes care practices. Mean differences in these scores were 1.3, 1.1 and 1.0 for the 
intervention group and $0.7,0.4$ and 0.3 for the control group respectively. Limitations of this study included an inability to determine which aspect of the learning map promoted positive change. In addition, it was not determined what contribution being in a small group made to positive outcomes.

McEwen, Pasvogel, Gallegos, and Barrera (2010) evaluated the efficacy of a culturally tailored diabetes self management social support intervention delivered to a group of 21 people with type 2 diabetes who were of Mexican American decent. A single group pre and post-test design was utilized to measure diabetes care behaviors and knowledge. Clinical control was measured by $\mathrm{Hb} \mathrm{Alc}$ and body mass index. A bilingual and bicultural certified diabetes educator and nurse researcher developed the intervention, which involved the use of a promotora or lay worker who was trained to reinforce selfmanagement practices to the group. Sessions consisted of six, 2 hour group sessions and included social support interventions at each session. Follow up measurements were taken at completion and at six months. McEwen et al. reported that there was improvement in diabetes self-management activities. There was a 0.74 effect size for mean diabetes self care activities after the intervention. A reduction in diabetes related distress was the most significantly impacted area after the intervention, with a 0.82 mean effect size in the area of emotional burden. The authors attributed this effect size to the impact of social support interventions. There was no significant change in physiological outcomes among the participants. 


\section{Health Effects of Psychological Support Groups}

Karlsen, Idsoe, Dirdal, Rokne-Hanestad, and Bru (2004) performed a randomized study that analyzed the effects of cognitive behavior therapy with problem solving and reinforcement on coping. The authors found stress and self-blame were reduced in the treatment group compared with the control group, but problem focused coping and psychological well being did not differ between the groups.

Using Kasl's Sixteen Step Mode Empowerment Model (Kasl, 1992) tailored to meet the individual needs of a group of diabetic women with type 1 and type 2 diabetes, Keane, Young, and Loos (2006) explored the efficacy of specialized support groups in treating diabetics. This model has been used to treat a variety of addictions and has been amended to treat various populations. The goal of the model was to help people who were dealing with addiction and dependency move through fear toward inner strength (Kasl, 1992). Seventeen women participated in ten weekly sessions of an addictionsspecific support group structure using Kasl's Model. The authors reported significant increases in diabetes self-efficacy scores post intervention compared to pre-intervention scores $(t=1.85 ; p=.05)$ suggesting that the support group fostered greater feelings of selfcontrol over their disease process. Eighty-eight percent of participants stated that they increased their adherence to self-care after participation in the support group. This study was significant as it is believed that there are many similarities between diabetes and addiction, including denial, minimization, and the need for alterations in lifestyle and that 
THE PERCEIVED IMPACT OF DIABETES

with specialized support, significant gains could be made. Limitations were that it did not include a control group and the small sample size.

\section{Perceived Impact of Mixed Diabetes Education/Support Groups}

Alley and Brown (2002) examined the emotional impact of combining both formal (educational component) and informal problem solving in an open-ended task centered model in a structured, ongoing support group. The authors postulated that by combining both informal and formal processes, the potential for usefulness would increase. The formal process consisted of the facilitator-teaching problem solving techniques. Concerns were addressed as the group's needs dictated. The informal process consisted of the group's decision regarding the flow and content of the meeting. The authors reported initial reluctance on the part of the group members to offer problem solving solutions, but within a few sessions, the participants gained confidence in their abilities to help others. When asked why they continued to return after the first session, the participants stated that the group helped them to problem solve and develop their own identities through sharing of a common experience. The group also helped them to identify what problems they needed to work on and offered opportunities for solutions. The authors suggested that persons within a diabetes support group will invest themselves in and offer help within the group when they feel that the group belongs to them. The authors promoted problem solving components into a support group to foster this sense of group ownership. 
Schreurs, Colland, Kuijer, deRidder, \& van Elderen (2003) examined the effects of a mixed support group among people with multiple chronic diseases including asthma, diabetes, and heart failure. Eighty-three participants underwent five two hour sessions disease specific information followed by strategies to promote behavior change. Included were goal setting and action plans each week with discussion of success or failure of action plans. Prior to the start of the sessions, participants answered questionnaires about their self-management behaviors and basic knowledge in order for the researchers to obtain baseline measurements. Seventy-two percent of the participants were satisfied with the number of sessions, and $92 \%$ were satisfied with the duration of the sessions. Homework assignments were rated less positively than the usefulness of goal setting and action planning $(\mathrm{t}[(57)]=3.98 ; \mathrm{p}<0.01)$. The $\mathrm{t}$ represents the number of participants who rated these aspects positively with the 3.98 representing the mean evaluation scores of all the participants in the areas of goal setting and action planning. Participants who were older tended to rate the action plan components more positively $(\mathrm{r}=0.46, \mathrm{p}<0.000)$. Twenty-three percent of participants wanted more sessions and $26 \%$ of participants would have preferred groups with more participants. The content of the sessions were rated the most positively by the participants, with most rating four out of five on a likert scale. The participants also stated that they learned a lot from their peers (Schreurs et al., 2003). 


\section{Perceived Impact of Support Groups}

Although there is substantial literature that provides information pointing to the relative effectiveness of mixed education/support groups on certain clinical and psychological outcomes, much less is known about the perceived benefits of diabetes support groups from the perspective of the participant. The majority of studies to date have examined the perceptions of parents whose children and adolescents utilize diabetes support groups, but the perceptions of adult participants living with diabetes requires further exploration.

According to Gottlieb, (2007) different types of support groups may provide different types of support for those living with chronic disease. These include: emotional support, such as empathy or compassion; tangible support, such as resources; and informational support, including referrals or learning about the personal experiences of others, which can be used to compare to one's own condition. Haber, Cohen, Lucas \& Baltes (2007) suggested that the subjective perceptions of a support group are what contribute to positive outcomes upon one's health. Purk (2004) performed a qualitative inquiry to assess what was helpful for people with a chronic illness who attend support groups. Members of five different support groups were interviewed to determine the impetus for the decision to participate in the support group. The participants stated that they joined the support group to meet others with the same condition and to get more information about their diagnosis. The author reported that support groups that offered education on diagnosis, treatment options, and coping were more likely to influence 
attendees' decision to participate. The participants reported that the support groups offered them a sense of empowerment. Married couples who attended the support group stated that the social aspect of the support group was important to them.

Percy, Gibbs, Potter and Boardman (2009) performed a qualitative inquiry to explore experiences of women who had polycystic ovarian disease and attended a monthly nurse led support group. Interviews with 13 women with polycystic ovarian disease were conducted using a semi- structured format. The authors described five themes that emerged as a result of the interviews: expectations and hope; socioemotional function; informational function; personal impact of the support group; criticisms and suggestions for change. Participants reported that the support group was a source of emotional support that provided them with a sense of empowerment and decreased isolation. The group dynamic acted as a motivator to self-manage their disease and was a source of new information and a forum to ask questions. However, the group members verbalized the desire to have less information from the experts and more opportunities for unstructured discussions.

Oftedal, Karlsen and Bru (2010) performed a study that examined how adults with type 2 diabetes perceived different attributes of support provided by healthcare practitioners and how various attributes of this support can influence peoples' motivation to self-manage their disease. Nineteen adults with type 2 diabetes were interviewed in focus groups. Five themes that reflected perceived attributes of support from healthcare practitioners emerged: an empathetic approach; practical advice and information; 
involvement in decision making; accurate and individualized information; and ongoing group-based support. The participants reported that support groups would enable them to share their experiences and fears and would be an important motivator to help them selfmanage their disease (Oftedal, Karlsen \& Bru, 2010).

In summary, diabetes self-management education groups have a positive impact upon clinical control and perceived quality of life at least in the short term, but the best educational strategy to sustain these effects long term remains unclear. The 2010 National Standards for Diabetes Self Management Education (Funnell et al., 2010) recognize the need for ongoing support to sustain the effects of diabetes education, but the role psychological support groups play in this remains uncertain. In addition, a lack of understanding of individual participant perceptions exists regarding the value and impact of diabetes psychological support groups upon physical and emotion well being as well as the actual process of how support groups can be structured to continue the effects of diabetes self management education groups. Understanding the basic tenets of the individual's own experience of being a participant in a diabetes support group is important to understand in order to facilitate effective support groups in the future and to plan programs for the growing number of individuals with diabetes needing treatment in the future. The purpose of this study was to explore the perceived impact of diabetes support groups among participants. Next the frameworks used to guide this study will be presented. 


\section{Theoretical Frameworks}

The theory of Stress, Appraisal, and Coping (Lazarus \& Folkman, 1984) and the Ecological Model (CDC) provided the theoretical guidance for this study. The former was utilized to provide the structure for the development of the interview questions as well as interpretation of results as they pertain to the individual's perceptions of diabetes support groups on a microscopic level. The latter was utilized as a model to provide assistance in interpretation, application, impact, and implications of findings within the context of the community.

Stress, Appraisal and Coping Theory. Lazarus first developed the theory of psychological stress in 1966. Lazarus and Folkman (1984) expanded upon Lazarus' original model to include concepts derived from more current research by Lazarus and others on perspectives of stress, coping, and adaptation. Included were more current research findings on the concepts of cognitive appraisal and coping. Stress, one component of the theory, is a complex process that is not purely physiological. It is the response to the relationship between the person and the environment, and how it is perceived or "appraised" by the person, which taxes or exceeds resources that endanger his or her well being.

Two processes affect the relationship between the person and the environment: cognitive appraisal and coping. During cognitive appraisal, there is an evaluation of why and to what degree the interaction between person and the environment evoke stress. The person tries to make meaning of an event. Coping is a process that consists of how the 
person manages the interaction with the environment and the perceived stress and the emotions that result (Lazarus \& Folkman).

Components of this theory suggest that cognitive appraisal occurs through interplay of both environmental and personal factors. Individual differences in the sensitivity and vulnerability to the stress as well as various interpretations and reactions to stress are results of an evaluative process. Cognitive appraisal, or evaluation of the situation, mediates the reaction to an event in the environment by attaching meaning or understanding to an event. Once a person attaches meaning to an event, an emotional reaction to the event occurs (Lazarus and Folkman).

Cognitive appraisals, primary and secondary, affect how a person copes with an event. The former is divided into three elements: irrelevant; benign-positive; and stressful. Irrelevant events are of no meaning or significance to the individual and are no cause for concern, as nothing can be lost or gained by the encounter. Benign-positive appraisals occur if there is a perception of possible positive outcomes of an event. These are positive appraisals that can produce pleasure. Stress appraisals constitute negative perceptions of an event and can induce fears of harm, threat, or loss. These can be actual or anticipated threats. Challenge, one form of stress appraisal, can be viewed as having both positive and negative elements. A challenge calls for the mobilization of coping efforts that will assist to focus on gain or potential gain. Threat and challenge can occur together at the same time. 
In secondary appraisals, new information provides an opportunity to reinterpret the stressor and employs the individual to weigh coping options to determine which strategy will work best. This reinterpretation can change the way a threat is perceived. Sometimes these are the results of coping efforts and are called defensive re-appraisals. Coping is a process which changes according to the context and can include defensive strategies, problem solving, and emotion focused coping (Lazarus \& Folkman).

Problem focused coping includes efforts to define the problem, generate solutions, and weigh a solution, and is likely to occur when a person feels that there are problems that can be effectively changed. Emotion focused coping, on the other hand, occurs more likely when a person feels that nothing can be done to modify or alter the threat or challenge. Both forms of coping can facilitate and impede each other and are used to manage internal and/or external demands (Lazarus and Folkman).

Coping is a continuous process and is the result of continuous re-appraisals after shifts in the person-environment. Coping should not be measured in outcomes, as this would ignore attempts to manage a stressor, but rather should be examined within the context of the efforts to manage a stress. Coping serves two functions: to manage a problem causing distress (problem focused coping) and regulating the emotional response to the problem (emotion focused coping) (Lazarus \& Folkman).

Significance of Lazarus' Stress, Appraisal and Coping Theory. The purpose of this study was to explore the perceived impact of diabetes support groups among participants. Problem and emotion focused coping, a component of diabetes care, may 
be facilitated by the dynamics of the support group, which can be examined from a participant's personal sense of physical and mental well-being. Individuals with diabetes use various forms of coping in their day-to-day living. The facets of on-going, daily care of diabetes bring many physical and emotional challenges. Problem focused coping strategies may help clients to manage their physical aspects of diabetes such as troubleshooting high and low blood sugars. Emotion focused coping can occur when individuals with diabetes struggle to manage the emotional impact that occurs when they recognize some tenants of care are a challenge and problems may not always be solvable.

Support groups may provide a source of problem solving and emotional support that enables one to cope with the physical and emotional challenges (stressors) of diabetes. These attempts to manage stressors, according to Lazarus and Folkman (1984), should be the indicator of successful coping rather than the outcome itself. It is in relation to this definition of coping by Lazarus and Folkman that the focus on subjective reports provided by the participants is grounded. Support groups can serve as a potential moderator or mediator of both interpersonal and situational stressors, thereby assisting the person with diabetes to employ problem focused coping if solutions are present and emotion focused coping if solutions are not present.

\section{Application of Lazarus' Stress, Appraisal and Coping Theory in Chronic}

Illness. Mok, Lai and Zhang (2003) employed the stress, appraisal, and coping theory (Lazarus \& Folkman, 1984) to examine the coping behaviors of patients with chronic renal failure in China. Using a qualitative design, 11 patients with chronic renal failure 
were interviewed individually to examine their perception of the problem, coping responses, and coping strategies. Major themes that emerged among the participants included coping with fluctuating feelings, adjusting to lifestyle changes and changing family roles, altered body image, stress, motivation for coping, emotional and problem focused coping strategies, and illness acceptance. Although this study was limited in part due to its method and small sample size, it was significant as it provided evidence that problem and emotion focused coping strategies were common elements among the cultures of the east and west.

Social Ecological Model. The Social Ecological Model (Appendix A) is a framework that acknowledges the interaction between the person and his/her environment. This model, originated by Urie Bronfenbrenner $(1977 ; 1979)$ in his ecological systems theory, described the continuous interaction of the person and the environment. The environment is shaped by individual, organizational, community, and cultural influences. This framework has been adapted many times, and within the context of health it is used as a framework to develop and evaluate various public health promotion programs. The CDC's (n.d.) adaptation was utilized for this study. Within the continuum of health and illness, this framework describes the interplay of individual, relationship, community, and societal factors that assist users to assess risk and protective factors (CDC, n.d.) for health and illness.

The Social Ecological Model addresses individual risk factors as well as societal norms, beliefs, and social and economic systems. Risk and protective factors for health 
and illness on a personal level include age, gender, income, education level, and lifestyle choice as well as attitudes and beliefs. Relationships at the interpersonal level include interaction with peers, family, friends, and partners. Community level influences include areas where people work, schools, churches, and neighborhoods. Societal influences are larger macro-level factors which occur at the broadest level. These represent social policies that can influence health and illness, cultural factors, and economic variables (CDC, n.d.).

The Social Ecological Model has been extensively used by the CDC to develop violence prevention programs. Robinson (2008) utilized this model to explain that poor dietary intake of fruits and vegetables among low income African Americans was a result of personal, cultural, and environmental factors and that interventions targeted at multiple levels need to be performed to increase fruit and vegetable consumption.

Significance of the Ecological Model. Individuals live within a broader social context. Support groups operate within the larger context of community and society. The importance of support groups can be examined not only on an individual level, but to the community in which support groups serve. This includes the community providing the infrastructure within which the support group exists and the society providing the resource allocation and policies which demonstrate that value is afforded to this means of treatment. The Ecological Model provides the theoretical basis for this macroscopic perspective. Next, the methods used to conduct this study will be presented. 


\section{Method}

\section{Purpose}

The purpose of this study was to explore the perceived impact of diabetes support groups among participants. To gain an awareness of this, the subjective experience of being a participant in a diabetes support group and impact on a person's physical and emotional well being was explored as well as the physical and emotional concerns that individuals living with diabetes struggle with.

\section{Design}

This study utilized an exploratory qualitative design that involved individual interviews.

\section{Sample}

The target sample included participants who were attending ongoing diabetes support groups at the East Providence Senior Center. Inclusion and exclusion criteria included that participants must have had a diabetes diagnosis for at least one year. The rationale for this was that participants who did not have a diagnosis of diabetes for at least one year may not have enough experience managing the disease or adequate exposure to diabetes support groups to provide the required information and perspective. Participants who did not attend at least four support group sessions were excluded from the study as it was felt that participants who had not attended a minimum of four sessions would not be able to provide information about the perceived benefits of a support group with sufficient detail. 


\section{Site and description of support group}

The East Providence Senior Center holds monthly diabetes support groups for the community. Anyone with diabetes is welcome to attend. The group usually meets the last Thursday of every month, and sessions last for ninety minutes. A licensed registered nurse who is a certified outpatient diabetes educator and who has a Master's in Health Education facilitates the support group. This is an ongoing support group and participants are free to join at any time and for any number of sessions. The support group employs an unstructured format, with incidental education occurring as issues and concerns arise. Each member is given a turn to speak about their concerns. The facilitator encourages the participants to assist each other in problem solving and uses these topics as an opportunity to educate participants about related issues. On the day of the recruitment, there were eight participants present, seven of which were female. There was one new female member present at that time.

\section{Procedures}

Prior to the application to Institutional Review Board (IRB) at Rhode Island College, the support group facilitator was contacted by the principal investigator to explain the study and to confirm or deny interest. At this time, interest was confirmed and an application was submitted to the IRB, which fully approved the study. The student investigator mailed an IRB approved informational letter to the support group facilitator. The letter explained the purpose and details of the study as well as the student investigator's contact information. Upon receipt of the letter, the support group 
facilitator contacted the student investigator to invite her to a regularly scheduled support group session in order to introduce and explain the study to potential participants.

At the date and time agreed upon, the student investigator attended a regularly scheduled support group meeting and introduced herself and the purpose of the study to the participants prior to their support group session. An IRB approved informational letter that included details of the study, that interviews would be conducted and tape recorded, as well as inclusion and exclusion criteria, were provided to interested participants. On the day of the meeting, eight support group participants were present, and five participants expressed interest in the study. Four participants arranged a convenient date and time for the student investigator to interview them, provided their contact information, and gave the student investigator permission to phone them the day prior to the interview to confirm continued interest in the study. Participants were phoned to reconfirm interest and all four participants confirmed continued interest.

On the day of the actual interview, the student investigator explained the study in detail and answered any questions that the participants had. The student investigator also again asked the participants' permission to tape record the interviews in order to recall information needed for transcription at a later date. All participants agreed to be tape recorded. The participants were also informed that the student investigator would be writing notes throughout the interview to enhance recall of the content from the interviews. Informed consent was then obtained by having the participants read and sign an IRB approved consent form (Appendix B). Basic demographic and illness related 
information was collected at the start of each interview, including type of diabetes, number of years with disease, history of formal diabetes education, other support group involvement, length of time in this support group, frequency of attendance, gender, culture/ethnicity, and age.

The participants were interviewed using a series of open-ended interview questions (Appendix C) developed by the student investigator which were designed to capture 1) the physical and emotional stressors that individuals with diabetes experience, 2) how support groups help with these challenges, and 3) the problem and emotion focused coping skills that the individuals employed and how the support group helped to facilitate coping. Lazarus and Folkman's (1984) Theory of Stress, Appraisal, and Coping served as a guide to the development of the interview questions. The concept of coping was utilized to explore the problem and emotion focused coping skills that the participants may have utilized and how the support groups help to facilitate coping within the context of physical and emotional challenges. Stress, another component of this model, guided questions that would allow the student investigator to examine what prevailing events in their disease or care (stressors) was difficult or challenging. This allowed the exploration of how particular stressors were perceived and appraised by the individuals. The interview questions were also considered within the context of the student investigators personal experiences with caring for individuals with chronic illness in the community. Figure 1 is a graphic depiction of the elements within Lazarus and Folkman's theory of Stress, Appraisal and Coping. The elements of stress and coping 
assisted the student investigator to develop the interview questions. This was instrumental in allowing the student investigator to explore the role of support groups in assisting the participants to deal with challenges related to diabetes, the problem and emotion focused coping that the individuals employed, and how the support group facilitated coping.

Interpersonal

Processes

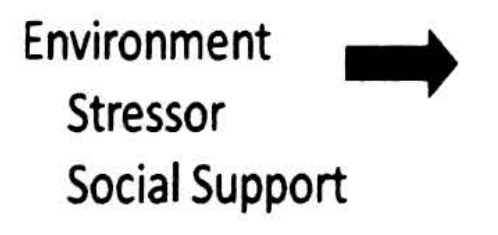

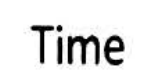

Outcomes

Somatic Health

Functioning Family Relationships Well being (Morale)

Figure 1. Graphic illustration of the components of Stress, Appraisal and Coping Theory (1984). Adapted from http://www.medscape.com. 
During the interview, a technique called member checking was utilized. This is a technique that ensures credibility whereby data from interviews is played back and tested with the interviewees, who correct errors of interpretations imposed by the researchers (Lincoln\& Guba, 1985). The interviews took approximately one hour each.

\section{Data Analysis}

The data was analyzed with respect to Lincoln and Guba's (1985) criteria to ensure credibility. Lincoln and Guba suggested four criteria for ensuring the trustworthiness of data in qualitative studies. These are: credibility, or confidence or truth of the interpretation of data; dependability, which reflects data that is the same or stable over time and in different conditions; confirmability, that two or more people come to the same conclusions about the data as well as that the data reflects the participants' voice and not the investigators; and transferability, which is the extent to which the data can be generalized or applied to other settings or groups (Lincoln \& Guba).

Credibility was achieved by summarizing discussions with each interviewee to maintain correct interpretation of data. To further ensure credibility, the student investigator and major advisor identified and systematically formulated themes from the field notes and transcripts. The dependability of this study was supported by the student investigator asking the same questions among all the participants and by transcribing the audio recordings verbatim. Confirmability was achieved by having the student investigator and the major advisor independently analyze the data and then analyze it together to decide on major themes that confirmed that the data reflected views of the 
participants. Transferability of this study's findings can be considered. In order to achieve this, the demographics of the participants were included in the interview process as well as the inclusion of quotations.

The student investigator transcribed the data verbatim. Subsequent analysis by the student investigator included analyzing the data from each interview and then comparing notes from each interview to look for similar patterns and themes. The major advisor received all transcripts as transcribed by the student investigator and analyzed the data independently, and then both reconvened to discuss findings. After the initial examinations of the data by the student and the major advisor, findings were discussed and areas of ambiguity were reconciled. This was done until all areas of discrepancy were resolved. 


\section{Results.}

\section{Demographic characteristics.}

Four participants completed the study. Table 1 represents the demographic characteristics of the study participants.

Table 1

Demographic Characteristics of Study Participants ( $n=4)$

\begin{tabular}{|l|l|l|l|}
\hline Characteristic & Category & Number & Mean (Range) \\
\hline Gender & $\begin{array}{l}\text { Male } \\
\text { Female }\end{array}$ & $\begin{array}{l}0 \\
4\end{array}$ & \\
\hline Age (years) & & 1 & $75.5(66-85)$ \\
\hline Ethnicity & $\begin{array}{l}\text { Foreign Born } \\
\text { US Born }\end{array}$ & 3 & \\
\hline Diabetes (type) & $\begin{array}{l}\text { Type 1 } \\
\text { Type 2 }\end{array}$ & 1 & $14(3-30)$ \\
\hline $\begin{array}{l}\text { Diabetes Duration } \\
\text { (years) }\end{array}$ & & & $2.5(1-3)$ \\
\hline $\begin{array}{l}\text { Length of Support } \\
\text { Group Involvement } \\
\text { (years) }\end{array}$ & & & $3.25(0-8)$ \\
\hline $\begin{array}{l}\text { Number of Previous } \\
\text { Diabetes Educational } \\
\text { sessions }\end{array}$ & & & \\
\hline
\end{tabular}

As demonstrated in the above table, all study participants were female. Three of the four participants had joined a support group immediately after their diabetes diagnosis. One participant had no diabetes support group involvement until joining this group. Seventy-five percent of the participants had type 2 diabetes.

In response to the exploration of physical and emotional challenges that the participants faced, three of the four participants reported various physical challenges and 
two participants reported emotional challenges associated with their disease. Table 2 demonstrates the various physical and emotional challenges that the participants experienced during a time in their illness as reflected by their answers to the following two questions: 1) what physical challenges do you have, if any, as a result of your diabetes and 2) what emotional challenges do you have, if any, as a result of your diabetes?

Table 2

Physical and Emotional Challenges

\begin{tabular}{|l|l|}
\hline \multicolumn{1}{|c|}{ Emotional Challenges } & \multicolumn{1}{c|}{ Physical Challenges } \\
\hline Anxiety & Complex Medication Regimen \\
\hline Fear & Medication Side Effects \\
\hline Shock & Fluctuating Blood Sugars \\
\hline Disbelief & Weight Gain \\
\hline Panic & Maintaining Diet \\
\hline Isolation & Neuropathic Pain \\
\hline & Difficulty Walking \\
\hline & Integrating Physical Activity \\
\hline
\end{tabular}

During the interviews it was evident that there was an ebb and flow to the physical and emotional challenges that the participants experienced. Some challenges were more enduring or difficult to manage. However, it was clear that integrating diabetes self-management behaviors was a challenge to most individuals with particular struggles related to diet and exercise.

After uncovering the physical and emotional challenges that the participants had experienced at some point along the trajectory of their illness, the student investigator 
then explored, as reflected in questions 2 and 3, how the support group helped the participants to cope with these challenges, the problem and emotion focused coping skills that the individuals employed and how the support group helped to facilitate coping.

The participants described the perceived impact of the support group from their experiences and how the support group helped them to cope with challenges related to diabetes. The participants displayed some problem and emotion focused coping strategies. Five salient themes that described the participant's voice and description of their support group experiences emerged: information, group trouble shooting, hope, shared experience, and behavior change. These were discovered by the student investigator who asked the following questions: 1) What challenges do you feel the support group has helped you with? 2) What skill(s) have you learned in the support group, if any, that have helped you to deal with the physical challenges of diabetes? 3) What behaviors are you doing differently since joining the support group? 4) How has the support group helped you to deal with emotional issues or concerns? 5) How has the support group affected your quality of life? Tables 3-7 identify the themes with corresponding examples to illuminate the findings.

The support group was a source of information exchange for all the participants. They learned through listening to the experiences of others, from the facilitator and any lecturers that joined the group. Table 3 provides examples of the learning that occurred within the group. 
Table 3

\section{Theme 1 Information}

"I see and learn a lot because many, like I told you before, that I did not go through such education or support group or something. I will tell you I know more."

"You hear every now and then it might be a little think like oh 'I'll try that like, it seems like it'll work."

"...You never know what you are going to learn."

"...so every time I go, I learn something new. Even if it is just a little thing."

"You learn sometimes something about the medication you are taking or the vitamins you are taking. They bring in the eye care specialist or the doctors, maybe the foot doctors so you learn."

The examples in table 3 represent the individual's description of the support

group as a source of information for them. It was perceived to be a great benefit. Table 4 represents the participants' explanation of group trouble shooting that occurred amongst group members.

Table 4

\section{Theme 2 Group Trouble Shooting}

"If you have anything that bothers you, you just bring it up and somebody will solve it for you."

"Oh, we learn from each other. It's very important. We learn more from each other than you probably learn from a piece of paper or a program."

The participants felt that group trouble shooting was a valuable asset. They actively engaged in problem solving for each other. The student investigator observed this firsthand when observation of the group occurred. 
The support group represented a source of hope for the participants. This provided them reassurance that they would be able to live a normal life. Table 5 provides examples of the how the support group helped to foster hope.

Table 5

Theme 4 Hope

"I sat here the whole time with tears in my eyes and was worried sick that this was what was gonna happen to me And I listened to people as they went around the table.... one lady is in her nineties and everybody seemed to be doing fine, and Maureen put it in such a way that it was a hopeful thing if you paid attention."

"You know when I found that other people had lived all these years and never had horrible things happen to them where they had to go on dialysis and stuff, I started to realize in the beginning that you know it does not have to be where I remember it from before. But if you pay attention to it and take care of yourself... and you're the only one that can do that."

"Maureen, she has such an influence that she know how to ah cope with people like that. She brings me peaceful times. She really good. She influence so well that now if I come to her, I feel right away quiet, not so anxious...I can tell her everything. She is better then psychiatrist. Better then psychologist."

"When I came to this first meeting and I found out that people were actually controlling things and living a normal life. That was what made me turn the corner."

The preceding examples demonstrated that the support group helped to de-mystify the notion that a diabetes diagnosis would ensure an ominous fate. They learned through listening to the experiences of others that diabetes was a controllable disease and that complications could be avoided with measures aimed at clinical control. This provided them with a sense of emotional comfort. 
Participants were able to share experiences in the support group, which was perceived to be a helpful aspect. Table 6 demonstrates the shared experiences that occurred within the support group.

Table 6

\section{Theme 5 Shared Experiences}

"So this give me a new light on how people suffer, how people go through, how they got this, everybody is talking about this..."

"You realize all these people that you don't even think about you know that have diabetes but you think about gee, I didn't know this one had and that one had diabetes."

"So this support group not only bring, you find physical, how people suffer from this, but mental. Help mental."

"You have to be connected to people. This make me connected."

"... but it's nice to hear everybody's stories and you get to know them more on a personal level....I do sympathize with those who do have emotional issues and you know it helps you to now them more on a personal level."

"...you learn things that are amazing. Some people have, gosh- some of the things that people have to go through. They tell their story and then you get someone new there and you think, 'Oh my goodness!' and you realize the things that go on."

"it's comforting to know that the people in that room are so intent on keeping their diabetes in check."

It's just nice knowing that there are other people out there that have this and want to stay well by doing everything they can to stay well cause like I said, your family and friends, they really don't understand if they are not experiencing it. Someone to confide in."

Through the sharing of experiences in this support group, the participants gained an awareness of others like them and this decreased their sense of isolation. They came to realize that they were not alone in dealing with this disease and they were able to find comfort in knowing that there were others like them. 
Table 7 provides examples of the participants' behaviors or self-management activities that were fostered by the motivation that others in the support group provided. Table 7

Theme V Behavior Change

"Just trying to stay on the stay on the straight and narrow."

"In eleven months I lost 110 pounds... and within a few months after that I came off the cholesterol medicine and I came off the high blood pressure medication."

"I probably gained close to thirty pounds in a year and a half and I know that I had to get it off and that's why I started going to a diabetic coordinator."

"... but you can control it and live a pretty normal life if you pay attention to what you do and that's what I followed for that last three years, and I can't say that it's been a big... it hasn't really been big, actually I feel healthier."

"I come here and walk the track here with another woman..."

Behavior and lifestyle changes were difficult for all participants. Maintaining proper diet and exercise was a particular struggle for the participants. Diabetes selfmanagement tasks were complex at times. The support group was perceived to be a motivator to achieve or maintain self-management needed to control their diabetes. 
Figure 2 is adapted version of the elements contained within Lazarus and Folkman's theory of Stress, Appraisal and Coping (1984). The elements of problem focused (information, group trouble shooting and behaviors) and emotion focused (shared experience and hope) coping that the participants demonstrated in this study have been added to the illustration to highlight the coping strategies exhibited by the participants.

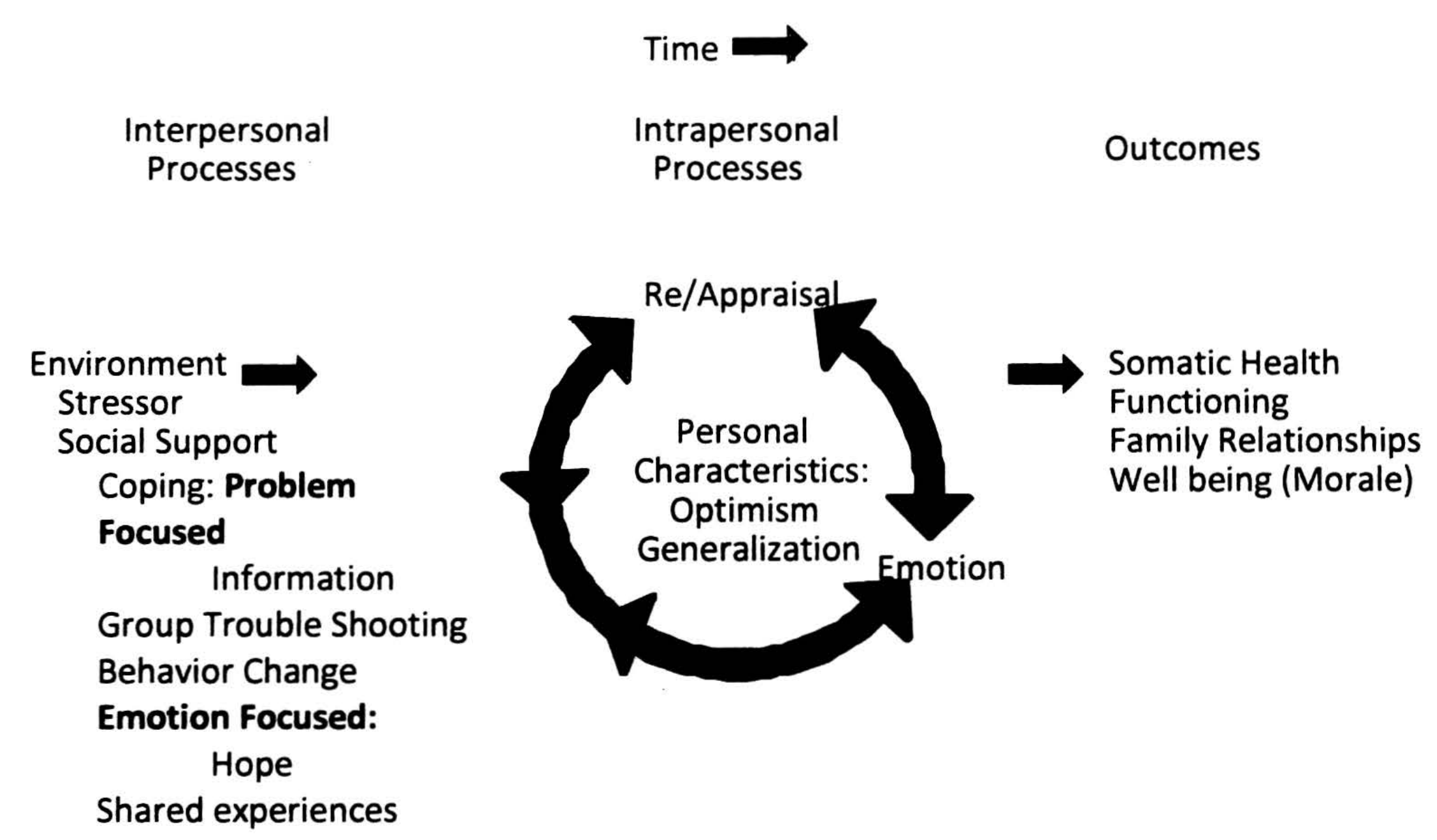

Figure 2. Adapted Illustration of Lazarus and Folkman's Theory of Stress, Appraisal and Coping from www.medscape.com. 
THE PERCEIVED IMPACT OF DIABETES

The individuals in this study displayed various problem and emotion focused coping strategies. Emotion focused coping was facilitated through shared experiences and hope that the support group provided them. These were utilized to cope with the emotional aspects of managing a chronic disease. Problem focused coping strategies were the behaviors utilized by the participants to perform self-management activities. These behaviors were facilitated by the information learned within the group and were demonstrated by group troubleshooting and individual self-management behaviors.

- Most individuals in the study reported physical and emotional challenges in relation to living with diabetes and this was clearly a source of difficulty on some level for them. However, their involvement within the support group assisted them to learn, exchange information, group trouble shoot, find hope, and share experiences while striving to maintain their control over their diabetes through behavior and lifestyle modification. The support group was perceived positively by all participants and each was grateful for having this support in the community. 


\section{Summary and Conclusions}

Diabetes is a pervasive disease which is extremely difficult to manage. Diabetes support groups offer a means of sustaining positive health behaviors and improving quality of life for those living with the disease. A dearth of research exists about the perception of diabetes support group participants related to the process, value, and impact of the support group experience. The evidence suggests that diabetes selfmanagement/education groups promote some positive outcomes at least in the short term (Clark,2008; Gamsu et al., 2002; Garrett et al, 2005; Karlsen et al.,2004; Kotani \& Sokane, 2004; McEwen et al.,2010 Saradi \& Rosenqvist, 2004; Trozzolini et al.,2003), but given mixed educational strategies with heterogeneous populations in a variety of group and individual settings, it remains unclear as to the best way to educate persons with diabetes (Clark,2008).

Much less is known about how support groups not focused on self-management education assist individuals living with diabetes. Alley \& Brown (2002) suggested that this is because most evaluations of support groups have examined clinical versus psychological outcomes. Evaluating the perceived impact of support groups is difficult since there is little evidence available. In addition, few studies have shown the positive psychological impact of support groups from the participants' point of view (Purk, 2004; Percy, 2009; Oftedal, 2010).

Diabetes self-management education, the efforts of which exist to help people learn the day- to- day tasks needed to manage diabetes, is in stark contrast to the basis of 
support groups, whose sole mission is to provide support. A person's need for support is ongoing, and support groups can offer this to a person living with diabetes.

The purpose of this study was to explore the perceived impact of a diabetes support group among participants. A small group of diabetes support group participants consented to the study and were interviewed one-on-one using a series of open-ended interview questions designed to examine the perceived impact of the diabetes support group. Some physical and emotional challenges that the participants experienced were revealed. The support group was a source of learning, information exchange, group trouble shooting, hope, and shared experiences as they strived to maintain or change behaviors necessary for health. It was also a source of problem and emotion focused coping among the individuals which affected their quality of life.

Among the participants, the diabetes support group was clearly a powerful tool to help motivate, educate, and empower. The support group dynamic provided a sense of hope that helped the participants to transcend the difficulties and challenges they faced, and assisted in de-mystifying any preconceived notions that diabetes was certain to predict an ominous future. On a personal level, participants were able to relate to each other through a series of dialogues, from which they came to realize that they were not alone in dealing with their disease. They found comfort in knowing that there were others like them, and through shared experiences, they were able to relate to each other to find their own unique identities within the group. 
Diabetes support groups can be a powerful entity for persons living with diabetes. In this study, it was evident that there was vast amount of information exchanged in the group, which enhanced the general knowledge base of the participants or acted to reinforce what they had previously learned throughout the course of their illness. The group dynamic acted as a motivator for self-management behaviors, despite acknowledgement that this was not always easy.

Emotional support among people dealing with similar issues provided a source of comfort in knowing that they were not alone. Equally important to these individuals was learning that diabetes is a manageable disease. Ongoing support helped clients in this study to self-manage their diabetes by providing them with the knowledge and confidence necessary to improve health. This was demonstrated by the practical information that participants found useful for their care.

The facilitator of this group demonstrated a positive role in each participant's care. This was clearly demonstrated by the participants' discussion of the facilitator despite not being directly questioned on this. Clearly, she was appreciated for her knowledge base, willingness to assist with issues, and her accessibility, which were of pivotal importance for these participants.

Limitations of this study included a small sample size, thus limiting generalization of findings beyond this group. Two questions in particular: "What behaviors are you doing differently as a result of being a participant in a support group?" and "What skills have you learned if any have helped you to deal with the physical 
challenges of diabetes?" were difficult for all respondents to answer. The investigator attributed this to mean that the language of the question was unclear to participants. While the participants all believed that they gained knowledge on a variety of topics such as diet, exercise and general topics related to diabetes, no one could name a skill that they learned as a result of being a participant in a diabetes support group. Skill seemed to be a word which possibly was understood as being a specific concrete task by participants. An attempt by the student investigator was made during the interviews to provide examples to the participants in order to clarify poorly understood questions, with careful attention not to lead the participant. Perhaps the difficulty participants had in these questions provides further indication that a support group's main role is to provide psychological support rather than to learn a specific skill or task.

In terms of behaviors, it was clear that the participants made attempts to follow diet and exercise regimens and that the group seemed to motivate individuals to engage in healthy lifestyle choices. However, it was difficult for the student investigator to understand if this was a result of the support group. Since three of the four participants had joined a support group right after their diagnosis, they had no experience dealing with the disease without a support group. Perhaps the inclusion of a control group that examined participants who were not utilizing support groups may have provided some clarity to this.

The study participants were all Caucasian females and thus were not representative of the general population. Since diabetes is equally prevalent in men and 
is also a disproportionately represented in minority subgroups, further study of those groups is indicated.

This study described some physical and emotional stressors that can burden individuals with diabetes and provided examples of how support can help to ease fear and anxiety and instill hope through a sharing of experiences among individuals who are engaging in lifestyle choices aimed at promoting health and wellness. Although no attempts were made to identify best strategies or processes that promote successful diabetes management and coping, it was helpful to learn about the struggles that individuals with diabetes deal with and how support groups help them. The National Guidelines for Diabetes Self-Management Education (Funnel et al., 2010) recommended ongoing support for people with diabetes with full recognition of the fact that we do not know how best to do this. Since there is scarce literature that describes the perceived impact of diabetes support group upon a person's physical and psychological being, this study contributes to understanding participants' perceptions of a support groups impact. 


\section{Recommendations and Implications for Advanced Practice Nursing}

Educational implications include the exposure of nursing students to a variety of settings where persons with diabetes gather and learn in order to gain an understanding of the complexity of the disease. Future nurses must have an understanding of the struggle of individuals living with diabetes and strategies to facilitate positive health outcomes for this growing population. Since minority groups share a disproportionate burden of diabetes, it is imperative for schools of nursing to expose students to diverse clinical settings and to culturally appropriate approaches to care. This is important not only for individual health, but for population health, where the tremendous diabetes related comorbidities impact upon the US health care system. Educational recommendations include the necessity of emphasizing the burden of morbidity and mortality of diabetes in the educational preparation of advanced practice nurses so that future practitioners will be cognizant of the needs of a population who will be more affected in the future.

Further research studies that examine the impact of diabetes support groups upon a person's physical and emotional being should be performed with the utilization of larger sample sizes. The inclusion of control groups to compare similar persons with diabetes who are using support groups with those who are not would provide further information. Insight into the strategies or interventions that can promote physical and emotional well being can be gained by measuring the effects of certain interventions against baseline status for predetermined outcomes. Advanced practice nurses play a pivotal role in designing further studies that will enlighten the health care community to 
determine what facets of support groups lead to favorable outcomes not only from a clinical outcomes perspective, but from a participant's subjective point of view.

The practice implications are clear. The health care system is evolving. From a financial perspective, programs that will be sustained are those that promote positive outcomes while preserving resources. Diabetes is a costly disease. Advanced practice nurses need to consider diabetes and its impact not only on the individual at a microscopic level, but macroscopically, on a global scale. The feasibility and utility of programs, from a financial perspective, should be considered when developing interventions and programs targeted to this population.

Diabetes self-management education is a reimbursable service made possible through the Balanced Budget Act. Unfortunately, to date, there is no reimbursement mechanism for support groups. This poses uncertainty as to the sustainability of this much needed support for persons living with chronic illnesses. Policy solutions include legislation that supports sustained funding for these groups. Advanced practice nurses can advocate for social health policies that promote this important tertiary public health intervention. Conversely, public health nurses recognize that primary prevention is crucial. A very small percentage of health care spending is applied to prevention activities in the US. Advanced practice nurses have an ethical responsibility to advocate for social health policies that promote population health, with an ever increasing need for prevention activities to be placed at the forefront of health care spending. This can be accomplished through gaining support from stakeholders and being visible to 
policymakers with suggestions for solutions and actions that benefit the health of the community. 


\section{References}

Alley, G.R., \& Brown, L.B. ( 2002). A diabetes problem solving support group. Social Work in Health Care, 36, (1),1-9.

The American Association of Diabetes Educators. (2010). AADE self care behaviors., Retrieved from http://www.diabeteseducator.org/Professional/Resources.

The American Diabetes Association [ADA] (2010). Diagnosis and classification of diabetes mellitus. Position statement. Diabetes care, 33, 62-69. Retrieved from: http://www.carediabetesjournals.org/content/33/supplement.

The American Diabetes Association. Diabetes Basics. Retrieved from http://www.diabetes.org/diabetes-basics/prevention/pre-diabetes.

Antonovsky, A. (1979). Health, Stress and Coping. San Francisco: Jossey Bass.

Calabretta, N. (2002). Consumer-driven patient-centered health care in the age of electronic information. Journal of Medical Library Association, 90, 32-37.

The Centers for Disease Control and Prevention [CDC] (2007a). National diabetes fact sheet 2007. Retrieved from: http://www.cdc.gov/diabetes/pubs/pdf/ndfs_2007.pdf.

The Centers for Disease Control and Prevention [CDC] (2007b). Take charge of your Diabetes. (4 $4^{\text {th }}$ ed.) Atlanta: U.S.Department of Health and Human Services. The Centers for Disease Control and Prevention [CDC] (n.d.). Violence prevention. The social ecological model. A framework for prevention. Retrieved from http://www.cdc.gov.ncipc/dvp/Social-Ecological-Model 
THE PERCEIVED IMPACT OF DIABETES

The Centers for Disease Control and Prevention [CDC] (2011). National diabetes fact sheet: National estimates and general information on diabetes and prediabetes in the United States ,2011.Atlanta Ga. U.S. Department of Health and Human Services.

Clark, M. (2008). Diabetes self-management education: A review of published studies. Primary Care Diabetes Europe, 113-120. Retrieved from: http://www.intl.elsevierhealth.com/journals/pcd

Conway, V., \& Terry, D. (1992). Appraised controllability as a moderator of the effectiveness of different coping strategies: A test of the goodness of fit hypothesis. Australian Journal of Psychology, 44, 1-7.

Costello, J. (2007). Roles and strategies of nurses facilitating diabetes support groups: An exploratory study. Doctoral dissertation. Retrieved from http://www.ric.edu/jamespadamslibrary.

Deakin, T., McShane, C.E., Cade, J.E., \& Williams, R.D. (2005). Group based training for self-management strategies in people with Type 2 diabetes mellitus. Cochrane Systematic Review.

Duangdao, K.M., \& Roesch, S.C. (2008). Coping with diabetes in adulthood: A metaanalysis. Journal of Behavioral Medicine, 31, 291-300.

Ellis, S., Speroff, R.S., Dittus , A., Brown, J.W., Pickett T.A., \& Elasy, T. ( 2004). Diabetes patient education: A meta-analysis and meta-regression Patient Education, 52, (1) 97-105. 
Fisher, E.B., Thorpe, C.T., McEvoy, Devellis-McEvoy, B., \& De Vellis, R.F. (2007). Healthy coping, negative emotions, and diabetes management: A systematic review and appraisal. The Diabetes Educator, 33, 1080-1103.

Funnell, M.M. Brown, T.L., Childs, B.P., Haas, L.B., Hosey, G.M., \& Jensen, B., .... Weiss, M. (2010). National standard for diabetes self- management education. Diabetes Care, 33, 89-96. Retrieved from: www.care.diabetesjournals.org.

Gamsu, D.S., Sutton, M.\& Ward, J.D. (2002). The development of a psycho-educational group intervention for overweight women with type-2 diabetes mellitus: a service evaluation. Practical Diabetes International, 19, (2), 43-50.

Garrett, N., Hageman, C.M., Sibley, S., Davern, M., Berger, M., Brunzell, C., ...Richards, S. (2005). The effectiveness of an interactive small group diabetes intervention in improving knowledge, feelings of control, and behavior. Health Promotion Practice, 6, (3), 320-328.

Gottlieb, B.H. 2000). Selecting and planning social support intervention. In Social Support Measurement and Intervention: A Guide for Health and Social Scientists. New York: Oxford University. 195-220.

Haber, M.G., Cohen, J.L., Lucas, T. \& Baltes, B.B. ( 2007). The relationship between self-reported received and perceived social support: A meta-analytic review. American Journal of Community Psychology, 39,133-14.

Harris, M.A. Wysociki , T., Sadler, M., Wilinson, K., Harvey, L.M., Buckloh, L.M.\& 
White, N.H.( 2000). Validation of a structured interview for the assessment of diabetes self-management. Diabetes Care , 23 ,1301-1305.

Karlsen, B. Idsoe,T., Dirdal ,I., Rokne-Hanestad, B., \& Brue, A. (2004). Effects of A group- based counseling programme on diabetes-related stress, coping, psychological well being and metabolic control in adults with type 1 or type 2 diabetes. Patient Education Counseling, 53, (3) , 299-308.

Kasl, C.D. (1992). Many roads, one journey. Moving beyond the twelve steps. New York: Harpers Collins.

Keane, S., Young, S., \& Loos, M. Similarities in diabetes and addiction: The exploration of the efficacy of specialized support groups in treating diabetes. Journal of Teaching in the Addictions, 4, (2) 93-110.

Knowler, W.C., Barrett-Connor, E., Fowler, S.E., Hamman, R.F., Lachim, J.M., Walker, E.A., \& Nathan, D.M. (2002). Reduction in incidence of type 2 diabetes with lifestyle intevention or metformin. New England Journal of Medicine, 346(6), $393-403$.

Kotani, K., \& Sakane, N. (2004). Effects of a self-help group for diabetes care in long-term patients with type-2 diabetes mellitus: An experience in a Japanese rural community. Australian Journal of Rural Health, $12,251-252$.

Lazarus, R.S., \& Folkman, S. (1993). Stress, appraisal, and coping. New York: Springer. 
Leichter, S. (1999). The business of diabetes education before and after new medicare regulations. Clinical Diabetes, 17, (3) Retrieved from: http://www.journaldiabetes.org/clinicaldiabetes/V17N31999/.

Lincoln, Y.S., \& Guba, E.G. (1985). Naturalistic inquiry. California: Sage.

Macrodimitris, S.D., \& Endler, N.S. (2001). Coping, control, and adjustment in Type 2 Diabetes. Health Psychology, 20, (3), 208-216.

McEwen, M.M., Pasvogel, A., Gallegos, G.,\& Barrera, L. (2010). Type 2 diabetes selfmanagement social support intervention at the U.S. Mexico Border. Public Health Nursing, 27,(4), 310-319.

Mensing, C.R.\& Norris, S.L. (2003) Group education in diabetes: Effectiveness and Implementation. Diabetes Spectrum, 16, 96-103.

Mok, E., Lai, C.,\& Zhang, Z.K.( 2004). Coping with chronic renal failure in Hong Kong. International Journal of Nursing Studies, 41, 205-213.

National Institute of Diabetes and Digestive and Kidney Diseases (2008). DCCT and EDIC. The diabetes complications and control trial and follow up study. Retrieved from http://diabetes.niddk.nih.gov/dm/pubs/control/.

Norris, S.L., Lau, J., Smith, S.J., Schmid, C.H., \& Engelgau, M.M. (2002). Self management education for adults with type 2 diabetes. Diabetes Care, 25, (7), 159-1171.

Oftedal, B., Karlsen,B., \& Bru, E.(2010). Perceived support from healthcare practitioners Among adults with type 2 diabetes. Journal of Advanced Nursing, 66, (7), 1500- 
1509.

Percy, C.A., Gibbs, T., Potter, L., Boardman, S. (2009). Nurse-led peer support group: Experiences of women with polycystic ovary syndrome. Journal of Advanced Nursing, 65, (10), 2046-2055.

Purk, J.K. (2004). Support groups: Why do people attend? Rehabilitation Nursing. $29,(2), 62-67$.

Sanden-Eriksson, B. (2000). Coping with type-2 diabetes. The role of coherence compared with active management. Journal of Advanced Nursing, 31, (6,) 1393-1397.

Sarkadi, A., \& Rosenqvist, T. (2004). Experienced based group education in Type 2 diabetes. A randomized controlled trial. Patient Education and Counseling, 53, 291-298.

Schreurs, K.M.G., Colland,V.T., Kuijer, R.G., deRidder, T.D.,\& van Elderen, T.( 2002). Development, content, and process evaluation of short self-management intervention in patients with chronic diseases requiring self-care behaviors. Patient Education and Counseling, 51,133-141.

Trozzolino, L., Thompson, P.S., Tansman, M.S., \& Azen, S.P. (2003). Effects of a psychoeducational group on mood and glycemic control in adults with diabetes and visual impairments. Journal of Visual Impairment and Blindness, 97, (4), 230-240.

UK Prospective Diabetes Study [UKPDS]. University of Oxford. From: http:// 
THE PERCEIVED IMPACT OF DIABETES

www.dtu.ox.ac.uk/ukpds trial/index.php.

US Department of Health and Human Services. [USDHHS] National Institutes of Health.

(1999). Conquering diabetes: A strategic plan for the $21^{\text {st }}$ century. Washington

DC: U.S. Government Printing Office.

US Department of Health and Human Services [USDHHS]. (2009). Healthy people

2020. Retrieved from:

http://www.healthypeople.gov/hp2020/Comments/default.asp.

US Department of Health and Human Services [USDHHS]. (1999). Healthy People

2010. Retrieved from: http://www.healthypeople.gov. 


\section{$+\quad$ Theoretical Framework Social-Ecological Model}

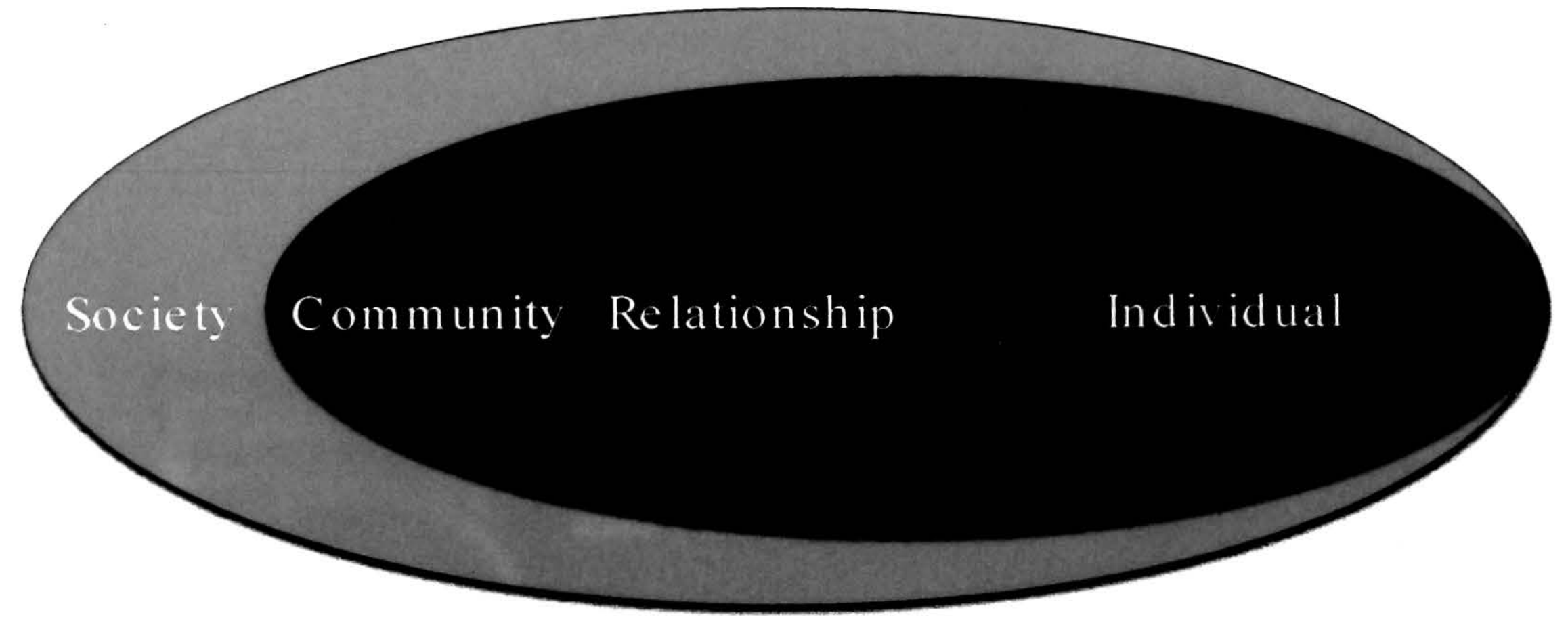

Dahlberg and Krug, 2002; CDC

Figure Al 
Consent Form

\author{
Appendix B
}

\title{
CONSENT DOCUMENT
}

\section{Rhode Island College}

\section{THE PERCEIVED IMPACT OF DIABETES SUPPORT GROUPS}

You are being asked to participate in a research study about the perceived impact of a diabetes support. You have been chosen to participate in this study because you have diabetes and you are a participant in a support group. Please read this form and ask any questions that you may have before agreeing to be in the research.

Rebecca Garofalo RN, a graduate nursing student at Rhode Island College, is completing this study.

\section{Background Information}

The purpose of this research is to explore your experiences of being in a support group and how it has helped you to deal with the physical and emotional aspects of diabetes.

\section{Procedures}

If you agree to be a participant in this research, you will be asked to do the following: You will be required to phone the researcher to schedule a meeting with her at a location and time convenient for you. The researcher will be able to come to your home if you desire. On the day before the interview, the researcher will phone you to confirm the interview. You will be interviewed by the researcher and will be asked to answer a series of questions about your diabetes and your experiences with it as well as your experiences that you have had as a participant in a diabetes support group. If you agree that it is acceptable to you, interviews will be tape-recorded. In addition to the tape recording, hand written notes will also be taken to help to recall the information from the interview. If you choose not to be tape-recorded, only hand written notes will be taken.

\section{Voluntary Participation}

Your participation is completely voluntary. If you choose not to participate in this research, there will be no negative consequences to you. Also, you can change your mind about participating at any time with no negative consequences. Choosing not to participate or changing your mind will not affect your relationship or standing with your support group that you attend or may attend in the future.

\section{Risks and Benefits to Being in the Study}

The risks of participating in this research are minimal, meaning that they are about the same as what you would experience in your normal daily activities. The main foreseeable risk is that you may feel that the interview may bring up emotions such as sadness or depression when you talk about your diabetes. Should you experience any of these emotions, the researcher will refer you to the facilitator of the support group for further support if you desire. You can withdraw from the study at any time. You will not be forced to answer anything that you do not feel comfortable with.

There is no direct benefit to you for participating in this study. Initial here to indicate that you have read and understood this page. 


\section{Appendix C}

Interview Questions

1. What physical challenges do you have if any, as a result of your diabetes?

2. What emotional challenges do you have if any, as a result of your diabetes?

3. What challenges do you feel the support group has helped you with?

4. What skill (s) have you learned in the support group, if any, that have helped you to deal with the physical challenges of diabetes?

5. How has the support group helped you to deal with emotional issues or concerns?

6. How has the support group affected your quality of life? 